\title{
Influencing Factors of Groundwater Organic Pollution around the Bosten Lake Area of Xinjiang, China
}

\author{
Ying Sun ${ }^{1,2}$, Jinlong Zhou ${ }^{1,2, *}$, Yinzhu Zhou ${ }^{3, * *}$, Yanyan Zeng ${ }^{1,2}$, and Yunfei Chen ${ }^{1,2}$ \\ ${ }^{1}$ College of Water Conservancy and Civil Engineering, Xinjiang Agricultural University, Urumqi, \\ 830052, P.R.China \\ ${ }^{2}$ Xinjiang Hydrology and Water Resources Engineering Research Center, Urumqi, 830052, P.R.China \\ ${ }^{3}$ Key Laboratory of Drinking Water Science and Technology, Research Center for Eco- \\ Environmental Sciences, Chinese Academy of Sciences, Beijing 100049, P.R.China
}

\begin{abstract}
To study the status and influencing factors of groundwater organic pollution around the Bosten Lake area (Kaidu River-Kongque River Basin), Xinjiang, China, the pollution index method was applied to 82 groundwater samples and 15 lake water samples for comprehensive pollution evaluation. Results showed that the detection rates of organic pollutants in groundwater and lake water samples in the study area are $24.4 \%$ and $6.7 \%$, respectively, but all the water samples have concentrations of organic pollutants less than the standard water quality limits. There are 11 unpolluted groundwater samples, 8 mildly polluted groundwater samples and one mid-polluted groundwater sample, accounting for $13.4 \%, 9.8 \%$ and $1.2 \%$ of total groundwater samples, respectively. The detection points of groundwater organic pollutants in the study area are mainly distributed in the piedmont plain area in the northern Yanqi Basin, the Yanqi County and the northwestern plain area of Bosten Lake. Some points sporadically distributed in the urban area in Korla. Groundwater organic pollution around the Bosten Lake area is mainly affected by industrial pollution, agricultural pollution, domestic pollution, vadose zone lithology, surface water quality and land utilization type.
\end{abstract}

\section{Introduction}

Organic pollutants in the groundwater environment have certain characteristics, including various categories, low concentrations, low detection limits and great hazards, etc [1]. Previous studies on the sources [2], influencing factors [3] and repair techniques of organic pollutants [4] in groundwater have been carried out.

In recent years, with the rapid development of petroleum, petrochemical, mineral, textile, agricultural by-products processing industries in the southern Tianshan area in Xinjiang, discharge of oil pollution, industrial wastewater and domestic sewage, garbage disposal and the abuse of pesticides and fertilizers have led to an increasingly serious

\footnotetext{
* Corresponding author: zjzhoujl@163.com (JL Zhou)

** Correspondence to: yinzhu_zhou@qq.com (YZ Zhou)
} 
groundwater organic pollution [1,5]. The Bosten Lake has a regulating effect on the inflow of Kaidu River and plays an important role in agricultural production, industrial water use and daily production and life in the counties and cities in the Kongque River Basin[6]. Wetland environment problem in the small lake area of Bosten Lake was serious in the past 30 years, and put forward corresponding protection measures[7]. The detection rate of groundwater organic pollution in Kaidu River Basin is $33.3 \%$, and three organic pollutants have been detected[3]. This paper is not only of great significance to the prevention and control of organic pollution in this area, but also provides important reference for protection of water environment, maintenance of ecological balance of the basin and rational allocation of water resources.

\section{Materials and research method}

\subsection{Study area}

Bosten Lake, the largest inland freshwater lake in China, is located in the southern of Tianshan Mountain, belonging to Xinjiang Bayinguoleng Mongolian Autonomous Prefecture. Its major recharge source is the Kaidu River. It is also the source of Kongque River as a natural large regulating reservoir (Fig.1).

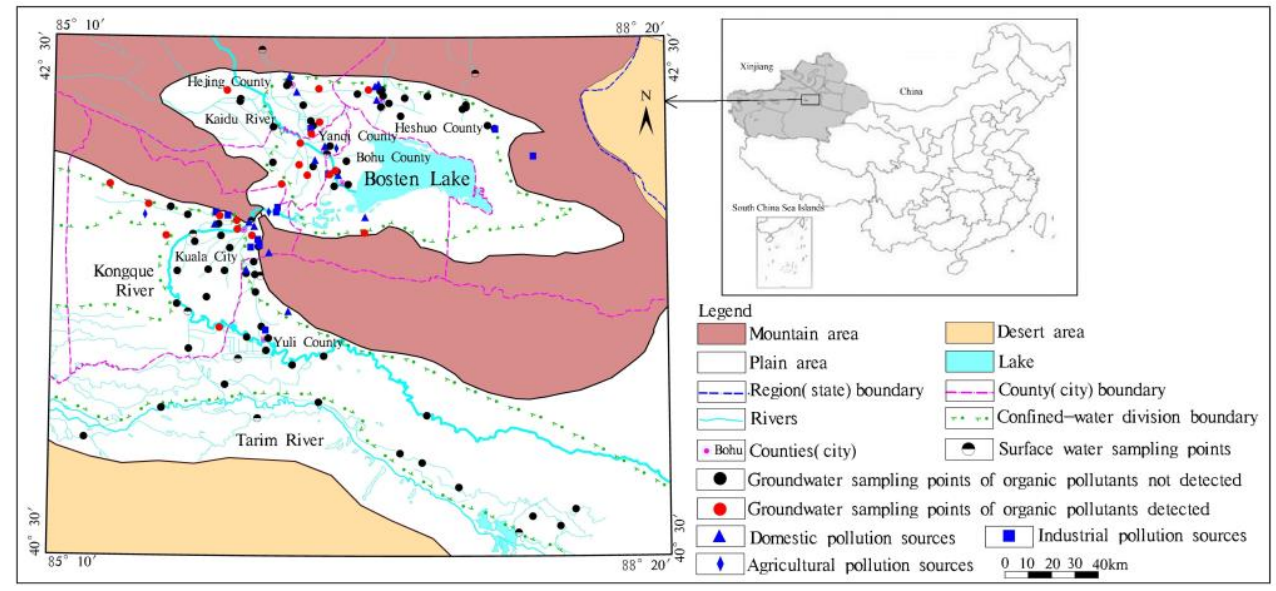

Fig. 1. Distribution of groundwater and surface water sampling points in the study area.

There are three types of landforms in the Kaidu River Basin, including the alluvial inclined plain (fine lithology and thick soil layer), the Kaidu River delta (accumulated by a large number of sediments and the permeability of rock layer is from good to poor) and the Bosten Lake Basin (a lowland area with shallow water) [1]. There are three geomorphic types of the Kongque River Basin including piedmont alluvial inclined gravel plain, piedmont alluvial inclined fine soil plain and alluvial fine soil plain, from the gravel plain to the fine soil plain, the slope changes from steep to gentle and the lithology is from coarse to fine. The study area is mainly composed of Quaternary loose rock pore water (phreatic water and confined water).

\subsection{Water sampling and evaluation method}

In June 2014, 82 groundwater samples were collected (including 29 phreatic water samples, 26 shallow confined water samples and 27 deep confined water samples). In addition, 15 
river water samples were collected. Twenty-seven volatile indicators and 12 semi-volatile indicators were tested in total.

According to the limits value of the Class III groundwater standard in the 'Groundwater Quality Standard (GB/T 14848-2017)', single factor pollution index was calculated using the measured value of a single indicator. The highest pollution level of the indicator in the water sample was taken as the comprehensive pollution level of water sample point [8].

$$
P_{k i}=\left(C_{k i}-C_{0}\right) / C
$$

Where $P_{\mathrm{ki}}$ is the pollution index of the i-th index in the k-th water sample; $C_{\mathrm{ki}}$ is the detection value of the $i$-th index in the $k$-th water sample; $C_{0}$ is the background value of $i$-th index of water sample; $\mathrm{C}$ is the Class III groundwater limit corresponding to the $\mathrm{i}$-th index in the standard.

\section{Results and analysis}

\subsection{Evaluation results of organic pollution}

Among 82 groundwater samples in the study area, 20 of which detected organic pollutants (detection rate of $24.4 \%$ ). All the groundwater samples have concentrations of organic pollutants less than the standard limit. Among 39 groundwater testing indicators, 7 of which were detected, including trans-1,2-dichloroethylene, cis-1,2-dichloroethylene, chloroform, 1,2-dichloroethane, toluene, tetrachloroethylene and 1,2-dichlorobenzene. Chloroform and toluene had higher detection rates of $14.6 \%$ and $7.3 \%$, respectively. Among 15 river water samples, one detected chloroform (with detection rate of $6.7 \%$ ).

The detection rates of groundwater sampling points in Yanqi County, Korla City, Hejing County, Bohu County, Heshuo County and Yuli County were $62.5 \%, 36.4 \%, 36.4 \%$, $33.3 \%, 7.1 \%$ and $0.0 \%$, respectively. The detection rates of phreatic water, shallow confined water and deep confined water in the study area were $27.6 \%, 23.1 \%$ and $22.2 \%$, respectively.

Among 20 groundwater samples detected organic pollutants in the study area, 11 were unpolluted, eight were mildly polluted and one medium polluted, accounting for $13.4 \%$, $9.8 \%$ and $1.2 \%$ of total groundwater samples, respectively. The pollution index of mildly polluted sampling points ranged from 0.0002 to 0.013 , with an average of 0.043 . While for of medium polluted sampling points, the pollution index was 0.348. The unpolluted sampling points were mainly distributed in the Yanqi County in northwestern Bosten Lake, Hejing County and the northern piedmont plain area of Korla City. The mildly polluted sampling points were mainly distributed in Hejing County, Bohu County and Korla City in the lower reaches of the Kaidu River. The medium polluted sampling points were distributed in the plain area of Korla City in the middle of the Kongque River.

\subsection{Genetic analysis of groundwater organic pollution}

\subsubsection{Type and distribution of pollution sources}

The industrial pollution sources in the study area include PetroChina crude oil stations, chemical plants and paper mills, which are the main sources of chloroform, 1,2dichloroethane, toluene,1,2-dichlorobenzene [9]. Wastes containing different organic components discharged by industrial production, such as a large amount of oily wastewater, harmful waste mud and other pollutants during petroleum products exploitation, processing 
and transportation, caused pollution of surrounding soil, rivers and groundwater [3]. The eight detected sampling points are located less than $10 \mathrm{~km}$ from the industrial pollution sources.

The agricultural pollution in the study area derived from farms and livestock farms. Precipitation and irrigation brought organic wastes from pesticides, fertilizers, farms and agricultural by-products into the aquifer, lead to groundwater quality degradation. There are agricultural pollution sources in the upper reaches of Kongque river and Yanqi county.

Domestic pollution in the study area mainly derived from sewage treatment plants and landfills, which are the main sources of chloroform, 1,2-dichloroethane, and toluene [10]. The leakage of domestic pollution during the treatment process may cause serious pollution to the groundwater. There was a lack of household waste disposal system in some rural areas, which leads to a widespread waste accumulation. In the upper Kongque River and Yanqi County, $30 \%$ of the detected sampling points are located less than $10 \mathrm{~km}$ from the domestic source of pollution.

\subsubsection{Vadose zone lithology}

According to groundwater table contour and the groundwater flow direction (Fig. 2), it can be seen that detected points of organic pollution were mainly concentrated in the lowwater-level area of groundwater and the area where the water level changed greatly, and the corresponding lithology were sub-clay and gravel respectively. The vadose zone in the study area is composed of sand and gravel, silty fine sand, sandy loam and loam with detection rates of $29.4 \%, 18.2 \%, 18.8 \%$ and $29.6 \%$, respectively.

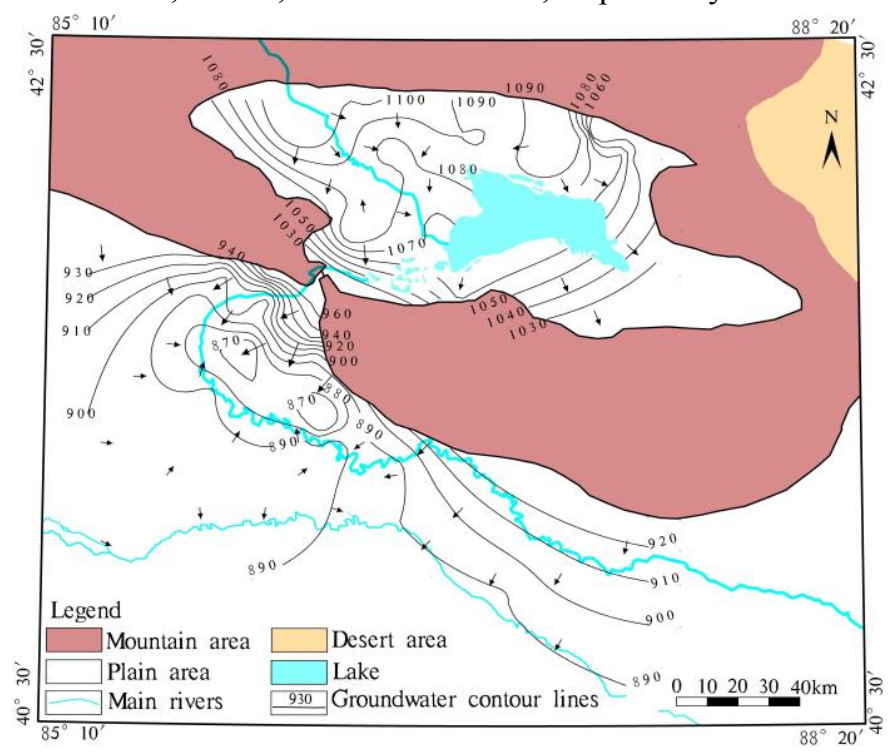

Fig. 2. Groundwater table contour in the study area.

The pollution-source density of the loam and sand and gravel were 0.44 and 1.33 point per $100 \mathrm{~km}^{2}$, respectively. Since the loam layer in the Kaidu River Basin was mainly distributed around Bosten Lake, with large pollution-source density, fine lithology and low penetrability, it is difficult for pollutants to migrate once they entered the aquifer [3]. The pollution-source density of sand and gravel distribution area in Kongque River Basin was greater with larger grain size and better permeability, which may facilitate pollutants infiltration into the soil through runoff and cause groundwater pollution [3]. 


\subsubsection{Surface water quality}

There are 15 river water sampling points around the Bosten Lake area, one of which detected chloroform. The sampling point is located in the loam distribution area around Bosten Lake, where there is an industrial pollution source and two sewage treatment plants. Two groundwater sampling points were detected at the detected surface water sampling points, and one of them was mildly polluted.

\subsubsection{Land use types}

The detection rates of groundwater organic pollution under different land-use types in the study area decreased in the order of pasture land (35.7\%), cultivated land $(25.0 \%)$ and construction land $(23.1 \%)$. Most of the study area was agricultural land. The abuse of pesticides, fertilizers and insecticides caused the migration of pollutants in soil into water body $[1,3]$.

\section{Conclusions}

Groundwater organic pollution in the area around the Bosten lake has been studied for the first time. Systematic research on status and influencing factors of groundwater organic pollution around the Bosten Lake has been carried out. Results showed that detection points of groundwater organic pollution in the area around the Bosten lake are mainly affected by the distribution of pollution sources (the upper reaches of Kongque river and Yanqi county), the vadose zone lithology (loam distributed in the low water level area and sand and gravel in the area where the water level changes greatly), surface water quality and land use types..

The survey was funded by NSFC-Xinjiang project "Transport of typical organic pollutants in the groundwater flow system of arid region and its risk assessment”, (U1503282).

\section{References}

1. J.T. Zhao, J.L. Zhou, Y.X. Gao, F.J. Luan, Q. Li, M.L. Du. China Envir. Scien., 36,1 (2016) (in Chinese)

2. L. Zhao. Urban Geol., 13,1 (2018) (in Chinese)

3. Y.Y. Zeng, J.L. Zhou, Y.Z. Zhou, R.L. Jia. Expo Health, 8,3 (2016)

4. C.J. Paradis. University of California, Davis (2014)

5. Y.N. Vodyanitskii, A.S. Yakovlev. Eurasian Soil Sci., 49,5 (2016)

6. Y.E. Ba, J.S. Guo, S.Y. Lu, Q.J. Xu, X.Z. Hu. China Envir. Scien., 33,3 (2013) (in Chinese)

7. Y. Wang, G.X. Li, Z.H. Li, Y.X. Ren. Transac. of Ocean. and Limn., 2 (2010) (in Chinese)

8. S.Z. Liu, C. Tian, Q.H. Sun, S.H. Liu. Shandong Land and Res., 33,1 (2017) (in Chinese)

9. H.M. Li, H.H. Chen, X.L. Zheng, D.Z. Zhang. Hydrogeol. Eng. Geol., 33,6 (2006) (in Chinese)

10. D.Y. Huang, S.G. Zhou, W Hong, W.F. Feng, L. Tao. Atmos Environ., 71, 3(2013) 